\title{
EDITORIAL
}

\section{Level of FEV1 as a predictor of all-cause and cardiovascular mortality: an effect beyond smoking and physical fitness?}

\author{
J. Sunyer* and C.S. Ulrik ${ }^{\#}$
}

I n 1970, HigGins and KelLer [1] showed that low spirometric values predict mortality independently of smoking in the general population of Tecumseh, MI, USA. Furthermore, in the general population of Renfrew and Paisley, Scotland, a forced expiratory volume in one second (FEV1) level in the lowest quintile explains a substantial fraction of all-cause mortality occurring in the subsequent $15 \mathrm{yrs}$ (31\% in males and $26 \%$ in females) [2]. This observation was mainly mediated through a higher risk of dying from cardiovascular conditions, as it has also been observed in a number of other cohorts. In line with this, a significant association has also been reported between baseline levels of lung function and the incidence of coronary heart disease [3] and stroke [4]; and, furthermore, annual decline of FEV1, independent of baseline FEV1, has also been related to cardiovascular mortality [5].

Recent evidence suggests that individuals in the community with moderate airflow limitation may have co-existing systemic inflammation [6], and this may therefore be the mechanism underlying the observed association between lung function and mortality. However, after adjusting for several peripheral inflammatory markers, the follow-up of 14,480 patients in the Atherosclerosis Risk in Communities study (ARIC) revealed a steady increase in the incidence of cardiac events (related to coronary artery disease) with decreasing quartiles of FEV1 [3].

Residual confounding by smoking, physical fitness, body mass index (BMI) or social class offer possible alternative explanations for the observed relationship between lung function and mortality. Although most of the reported findings from population studies have been adjusted for smoking habits and BMI, only very few have incorporated changes in these variables beyond baseline. Furthermore, an association has also recently been reported between physical inactivity and lower FEV1 [7], but this aspect has only been considered in very few studies. Moreover, even fewer studies have considered the role of socio-economic factors for the level of lung

*Environmental and Respiratory Research Unit, IMIM, Pompeu Fabra University, Barcelona, Catalonia, Spain. \#Dept of Respiratory Diseases, Hvidovre Hospital, University of Copenhagen, Copenhagen, Denmark.

CORRESPONDENCE: J. Sunyer, Inst. Municipal D'Investigacio Medica, c/ Dr Aiguader, 80 Barcelona, E-08003, Spain. Fax: 34 932213237. E-mail: jsunyer@imim.es function [8], and these factors therefore remain as an alternative explanation for the observed association.

STAVEM et al. [9] in this issue of the European Respiratory Journal report findings from a 26-yr follow-up study of 1,223 healthy males, aged 40-59 yrs at enrolment, from five companies in Oslo, Norway. In the total sample, the relative risk of all-cause mortality increased by $10 \%$ for each $10 \%$ decrease in FEV1 \% predicted, after adjusting for smoking habits, physical fitness, blood pressure, BMI and total cholesterol at baseline, as well as changes in smoking habits during the first $8 \mathrm{yrs}$ of the observation period. The corresponding relative risk increased by $7 \%$ for cardiovascular deaths. However, surprisingly, after stratifying by smoking category, these associations were no longer significant among the 398 never-smokers (relative risk $=1.01$ for all and 0.93 for cardiovascular causes).

This study contributed new knowledge primarily because it included a reliable objective measure of physical fitness at baseline. Few of the previously published studies on mortality have incorporated physical fitness, which is known to be a predictor of mortality [10], and to our knowledge none of these studies have included an objective test. Furthermore, the observed association between FEV1 and mortality was not confounded by physical fitness. This study, therefore, is likely to rule out residual confounding by physical inactivity as the driving mechanism behind the association between level of lung function and mortality. Another question of interest not addressed by STAVEM et al. [9] is whether exercise may modify the role of impaired FEV1 on mortality.

The lack of association among never-smokers may suggest residual confounding by smoking. However, the likelihood of residual confounding by smoking in the association between level of FEV1 and mortality seems unlikely given the large number of studies finding a positive association with cardiovascular mortality in never-smokers [2, 11-13]. The observed lack of association between FEV1 and mortality in neversmokers reported from the study by STAVEM et al. [9] is, therefore, most likely due to the relatively limited sample size. Nevertheless, larger studies or pooling data from a number of studies may be necessary to obtain a definitive answer to this question.

The lack of repeated measures of BMI and information on socio-economic determinants are the major limitations of this study, the former not least because changes in BMI may be 
considerable after changes in smoking habits [14]. However, general health and quality of life are related with socioeconomic conditions, in part because of poorer access to education and health services [8], higher exposures to air pollutants or occupational exposures [15], and the consequences of early life events, such as maternal diet or pre- and post-natal exposures, including diet [16] and environmental tobacco smoke [17], for the development of lung function.

In conclusion, the study by STAVEM et al. [9] provides new insight into the association between level of lung function and all-cause and cardiovascular mortality by documenting that this relationship cannot be explained solely by tobacco exposure and poor physical fitness.

\section{REFERENCES}

1 Higgins MW, Keller JB. Predictors of mortality in the adult population of Tecumseh. Arch Environ Health 1970; 21: 418-424.

2 Hole DJ, Watt GC, Davey-Smith G, Hart CL, Gillis CR, Hawthorne VM. Impaired lung function and mortality risk in men and women: findings from the Renfrew and Paisley prospective population study. BMJ 1996; 313: 711-715.

3 Schroeder EB, Welch VL, Couper D, et al. Lung function and incident coronary heart disease: the Arteriosclerosis Risk in Communities Study. Am J Epidemol 2003; 158: 1171-1181.

4 Truelsen T, Prescott E, Lange P, Schnoho P, Boysen G. Lung function and risk of fatal and non-fatal stroke. The Copenhagen City Heart Study. Int J Epidemiol 2001; 30: 145-151.

5 Tockman MS, Pearson JD, Fleg JL, et al. Rapid decline in FEV1. A new risk factor for coronary heart disease mortality. Am J Respir Crit Care Med 1995; 151: 390-398.

6 Sin DD, Man SF. Why are patients with chronic obstructive pulmonary disease at increased risk of cardiovascular diseases? The potential role of systemic inflammation in chronic obstructive pulmonary disease. Circulation 2003; 107: 1514-1519.
7 Jakes RW, Day NE, Patel B, et al. Physical inactivity is associated with lower forced expiratory volume in 1 second: European Prospective Investigation into CancerNorfolk Prospective population Study. Am J Epidemiol 2002; 156: 139-147.

8 Shohaimi S, Welch A, Bingham S, et al. Area deprivation predicts lung function independently of education and social class. Eur Respir J 2004; 24: 157-161.

9 Stavem K, Aaser E, Sandvik L, et al. Lung function, smoking and mortality in a 26-year follow-up of healthy middle-aged males. Eur Respir J 2005; 25: 618-625.

10 Sandvik L, Erikssen J, Thaulow E, Erikssen G, Mundal R, Rodahl K. Physical fitness as a predictor of mortality among healthy, middle-aged Norwegian men. $N$ Engl J Med 1993; 328: 533-537.

11 Strachan DP. Ventilatory function, height, and mortality among lifelong non-smokers. J Epidemiol Community Health 1992; 46: 66-70.

12 Curb JD, Marcus EB, Reed DM, MacLean C, Yano K. Smoking, pulmonary function, and mortality. Ann Epidemiol 1990; 1: 25-32.

13 Lange P, Nyboe J, Appleyard M, Jensen G, Schnohr P. Spirometric findings and mortality in never-smokers. J Clin Epidemiol 1990; 43: 867-873.

14 O'Hara P, Connett JE, Lee WW, Nides M, Murray R, Wise R. Early and late weight gain following smoking cessation in the Lung Health Study. Am J Epidemiol 1998; 148: 821-830.

15 Moulin JJ, Wild P, Mantout B, Fournier-Betz M, Mur JM, Smagghe G. Mortality from lung cancer and cardiovascular diseases among stainless-steel producing workers. Cancer Causes Control 1993; 4: 75-81.

16 Gilliland FD, Berhane KT, Li YF, Gauderman WJ, McConnell R, Peters J. Children's lung function and antioxidant vitamin, fruit, juice, and vegetable intake. $\mathrm{Am}$ J Epidemiol 2003; 158: 576-584.

17 Tager IB, Munoz A, Rosner B, Weiss ST, Carey V, Speizer FE. Effect of cigarette smoking on the pulmonary function of children and adolescents. Am Rev Respir Dis 1985; 131: 752-759. 